\title{
Properties of cytosolic components activating rat hepatic 5-deiodination in the presence of NADPH
}

\author{
Kenzo SAWADA, Brian C. W. HUMMEL, and Paul G. WALFISH* \\ The Thyroid Research Laboratory, Mount Sinai Hospital Research Institute and Endocrine Division, Mount Sinai Hospital, \\ and Department of Medicine, University of Toronto Medical School, Toronto, Ontario, Canada
}

\begin{abstract}
The effects of cytosol, NADPH and reduced glutathione (GSH) on the activity of 5'-deiodinase were studied by using washed hepatic microsomes from normal fed rats. Cytosol alone had little stimulatory effect on the activation of microsomal 5'-deiodinase. NADPH had no stimulatory effect on the microsomal 5 '-deiodinase unless cytosol was added. 5'-deiodinase activity was greatly enhanced by the simultaneous addition of NADPH and cytosol $(P<0.001)$; this was significantly higher than that with either NADPH or cytosol alone $(P<0.001)$. GSH was active in stimulating the enzyme activity in the absence of cytosol, but the activity of $5^{\prime}$-deiodinase with $62 \mu \mathrm{M}$-NADPH in the presence of cytosol was significantly higher than that with $250 \mu \mathrm{M}-\mathrm{GSH}$ in the presence of the same concentration of cytosol $(P<0.001)$. The properties of the cytosolic components essential for the NADPH-dependent activation of microsomal 5 -deiodinase independent of a glutathione/glutathione reductase system were further assessed using Sephadex G-50 column chromatography to yield three cytosolic fractions (A, B and C), wherein A represents pooled fractions near the void volume, B pooled fractions of intermediate $M_{\mathrm{r}}$ (approx. 13000), and C of low $M_{\mathrm{r}}$ (approx. $300)$ containing glutathione. In the presence of NADPH ( $1 \mathrm{mM})$, the $5^{\prime}$-deiodination rate by hepatic washed microsomes is greatly increased if both A and B are added and is a function of the concentrations of A, B, washed microsomes and NADPH. A is heat-labile, whereas B is heat-stable and non-dialysable. These observations provide the first evidence of an NADPH-dependent cytosolic reductase system not involving glutathione which stimulates microsomal 5'-deiodinase of normal rat liver. The present data are consistent with a deiodination mechanism involving mediation by a reductase (other than glutathione reductase) in fraction A of an NADPH-dependent reduction of a hydrogen acceptor in fraction B, followed by reduction of oxidized microsomal deiodinase by the reduced acceptor (component in fraction B).
\end{abstract}

\section{INTRODUCTION}

It has been reported that thiol compounds such as DTT, 2-ME and GSH are essential for the full stimulation in vitro of microsomal 5'-deiodinase (5'-DI) in rat liver and kidney (Visser et al., 1976; Chopra, 1978; Leonard \& Rosenberg, 1978). Although this stimulatory effect is not fully understood, the mechanism is believed to be the reduction to its original state of the deiodinase, which becomes oxidized during deiodination, as shown in the following scheme (Visser, 1979; Leonard \& Rosenberg, 1980a):

$$
\begin{gathered}
\mathrm{T}_{4}+\mathrm{E}-\mathrm{SH} \rightarrow \mathrm{T}_{3}+\mathrm{E}-\mathrm{SI} \\
\mathrm{E}-\mathrm{SI}+2 \mathrm{R}-\mathrm{SH} \rightarrow \mathrm{E}-\mathrm{SH}+\mathrm{R}-\mathrm{S}-\mathrm{SR}+\mathrm{HI}
\end{gathered}
$$

where $\mathrm{E}$ represents 5 -DI, believed to be the same enzyme mediating the monodeiodination of both $\mathrm{T}_{4}$ and $\mathrm{rT}_{3}$ (Visser, 1978; Visser et al., 1979). E-SI represents an enzyme-sulphenyl iodide intermediate, and $\mathrm{R}-\mathrm{SH}$ represents a thiol, such as DTT and GSH.

The relative abundance of endogenous GSH in cytosol (Tietze, 1969), the stimulation of microsomal 5'deiodination in vitro by the addition of exogenous GSH
(Chopra, 1978), and studies on the stimulation by GSH and NADPH of depleted hepatic deiodinase activity in starved rats, as well as in foetal liver, have led to the hypothesis that endogenous GSH and/or NADPH may function as a cofactor in the activation of $5^{\prime}$-DI (Balsam \& Ingbar, 1979; Balsam et al., 1979; Harris et al., 1979), the augmenting action of NADPH being ascribed to its effect on the generation of GSH through glutathione reductase (Balsam \& Ingbar, 1979; Balsam et al., 1979; Harris et al., 1979).

Other investigators, however, have shown that there is poor correlation between tissue glutathione concentrations and $5^{\prime}$-DI activities in rat liver as well as in primary cultured rat hepatocytes (Gavin et al., 1980; Sato \& Robbins, 1981). As suggested by Sato \& Robbins (1984), these findings indicate that microsomal deiodinase activity is not regulated by the tissue concentration of GSH in a simple manner.

The influence of NADPH on the activity of $5^{\prime}$-DI of microsomes as well as homogenates from normal fed rats has been a controversial subject for some time (Visser et al., 1975; Chiraseveenuprapund et al., 1978; Balsam \& Ingbar, 1979; Balsam et al., 1979; Harris et al., 1979; Sato

Abbreviations used: DTT, dithiothreitol; 2-ME, 2-mercaptoethanol; $5^{\prime}$-DI, $5^{\prime}$-deiodinase; $\mathrm{T}_{4}$, thyroxine; $\mathrm{rT}_{3}$, reverse tri-iodothyronine; $\mathrm{BSA}$, bovine serum albumin; $\mathrm{Nbs}_{2}, 5,5^{\prime}$-dithiobis-(2-nitrobenzoic acid); 3,3'- $\mathrm{T}_{2}, 3,3^{\prime}$-di-iodothyronine.

* To whom correspondence and reprint requests should be sent at the following address: Mount Sinai Hospital, Endocrine Unit, Suite \#640, 600 University Avenue, Toronto, Ontario M5G 1X5, Canada. 
et al., 1981). Data obtained with rat liver homogenates stored for 3 weeks at $-20^{\circ} \mathrm{C}$, and thus presumably depleted of NADPH and GSH, indicated that stimulation of deiodinase activity by added NADPH could not be accounted for in terms of GSH generation from GSSG (Sato et al., 1981).

Recent preliminary reports from our laboratory have demonstrated an essential role of cytosol in mediating the stimulatory effect of NADPH in the stimulation in vitro of $5^{\prime}$-DI from rat liver (Sawada et al., 1985a,b). In the present paper we have examined the effects of cytosol, NADPH and GSH on 5'-DI activity in a microsomal preparation from livers of normally fed rats. Furthermore, we have obtained by chromatography on Sephadex G-50 of rat hepatic cytosol two non-GSH fractions (A and B), both of which are of distinctly higher $M_{\mathrm{r}}$ than GSH, which are required simultaneously for the stimulation in vitro of 5'-DI in the presence of NADPH, thus providing evidence for a hitherto undescribed reducing system which activates rat hepatic microsomal 5'-deiodination but does not involve a glutathione-glutathione reductase system.

\section{MATERIALS AND METHODS}

\section{Reagents}

The reagents used in the present study were of reagent grade or the highest available purity. [ $\left.{ }^{125} \mathrm{I}\right] \mathrm{rT}_{3}$ $(100 \mu \mathrm{Ci} / \mathrm{ml}$; sp. radioactivity $>1200 \mu \mathrm{Ci} / \mu \mathrm{g})$ labelled with ${ }^{125} \mathrm{I}$ in the outer $\left(3^{\prime}\right.$ or $\left.5^{\prime}\right)$ ring was purchased from The Radiochemical Centre (Amersham, Bucks., U.K.). NADPH, GSH, GSSG, glutathione reductase (from yeast; type III; 170 units/mg of protein) and BSA were obtained from Sigma Chemical Co. (St. Louis, Mo, U.S.A.). Sephadex G-50 (fine grade), ribonuclease A and Blue Dextran were obtained from Pharmacia Fine Chemicals (Uppsala, Sweden). Estimation of thiol content of GSH, performed with $\mathrm{Nbs}_{2}$ by the method previously described (Riddles et al., 1983) indicated the purity of GSH which we used to be more than $80 \%$.

\section{Preparation of cytosol and microsomes}

Young male Sprague-Dawley rats (7-11 weeks of age when killed) maintained on standard chow ad libitum were used. Animals were killed and the livers weighed, minced in $0.9 \% \mathrm{NaCl}$, washed twice with $0.125 \mathrm{M}$ phosphate buffer, $\mathrm{pH} 7.4$, containing $1.0 \mathrm{~mm}$-EDTA (PBEDTA) and homogenized with a Polytron homogenizer (Brinkmann Instruments, Westbury, NY, U.S.A.) for $45 \mathrm{~s}$ in PB-EDTA ( $3 \mathrm{ml} / \mathrm{g}$ of liver tissue) at $4{ }^{\circ} \mathrm{C}$. Cytosol and microsomes were prepared by standard differential centrifugation. The homogenate was centrifuged at $2000 \mathrm{~g}$ for $10 \mathrm{~min}$ at $4{ }^{\circ} \mathrm{C}$ and the supernatant was centrifuged at $10000 \mathrm{~g}$ for $20 \mathrm{~min}$ at $4{ }^{\circ} \mathrm{C}$. The postmitochondrial supernatant thus obtained was ultracentrifuged at $100000 \mathrm{~g}$ for $60 \mathrm{~min}$ at $4{ }^{\circ} \mathrm{C}$, yielding supernatant (' $100000 \mathrm{~g}$ supernatant') and a pellet (' $100000 \mathrm{~g}$ pellet'). The $100000 \mathrm{~g}$ supernatant was further ultracentrifuged at $160000 \mathrm{~g}$ for $60 \mathrm{~min}$ at $4{ }^{\circ} \mathrm{C}$, stored at $-70^{\circ} \mathrm{C}$ and used as cytosol within 4 weeks. The $100000 \mathrm{~g}$ pellet was washed three times with PB-EDTA by ultracentrifugation, stored at $-70^{\circ} \mathrm{C}$ and used as the microsomal fraction within 4 weeks.

\section{Dialysis}

Cytosol was dialysed overnight at $4{ }^{\circ} \mathrm{C}$ against a 1000 -fold volume of PB-EDTA.
Fractionation of cytosol by Sephadex G-50 column chromatography

A $5 \mathrm{ml}$ portion of cytosol (containing about $102 \mathrm{mg}$ of protein) was applied to a column $(1.5 \mathrm{~cm} \times 64 \mathrm{~cm})$ of Sephadex G-50 and $2.0 \mathrm{ml}$ fractions were collected by the use of PB-EDTA as an elution buffer. Blue Dextran, ribonuclease $\mathrm{A}\left(M_{\mathrm{r}}=13700\right)$ and $\mathrm{GSH}\left(M_{\mathrm{r}}=307\right)$ were used as $M_{\mathrm{r}}$ standards.

\section{Determination of $5^{\prime}$-DI activity}

The assay method used to determine 5 -DI activity was based on measurement of free ${ }^{125} I^{-}$released from the outer-ring-labelled $\left.{ }^{[25} \mathrm{I}\right] \mathrm{rT}_{3}$ substrate employed, being a modification of the method which used an ion-exchange column to obtain released free ${ }^{125} \mathrm{I}^{-}$(Leonard \& Rosenberg, 1980b), using a more rapid trichloroacetic acid precipitation method to recover free ${ }^{125} \mathrm{I}^{-}$in the supernatant as previously reported (Fekkes et al., 1983) and recently performed in our laboratory (Sawada et al., $1985 c$ ). Rates of $5^{\prime}$-deiodination measured using the trichloroacetic acid method were reported to be the same as those obtained by measuring $3,3^{\prime}-\mathrm{T}_{2}$ using radioimmunoassay (Fekkes et al., 1983).

The present assay method using outer-ring-labelled ( $3^{\prime}$ or $\left.5^{\prime}\right)\left[{ }^{125} \mathrm{I}\right] \mathrm{r} \mathrm{T}_{3}$ as a substrate has been widely accepted as a rapid assay of $5^{\prime}$-DI activity (Leonard \& Rosenberg, $1980 b$; Visser et al., 1982; Fekkes et al., 1983). Furthermore, it has been widely accepted that the sole products of $\mathrm{rT}_{3}$ deiodination during the short incubation conditions employed in the assay are $3,3^{\prime}-\mathrm{T}_{2}$ and $\mathrm{I}^{-}$, which are generated in equivalent amounts, and that $3,3^{\prime}-T_{2}$ degradation during a short incubation (such as $15 \mathrm{~min}$ ) is negligible (Hufner \& Grussendorf, 1978; Visser et al., 1978, 1982; Eisenstein et al., 1980; Leonard \& Rosenberg, 1980b).

Briefly the assay was performed as follows. In experiments on the reconstitution of microsomes with cytosol, the reaction mixtures consisted of the microsomal preparation $(22 \mu \mathrm{g}$ of protein), cytosol (2000 $\mu \mathrm{g}$ of protein), $\left.{ }^{125} \mathrm{I}\right] \mathrm{rT}_{3}$ in PB-EDTA [105 c.p.m. final $\mathrm{rT}_{3}$ substrate concentration of $0.21 \mathrm{nM}$, estimated $K_{\mathrm{m}}=64 \mathrm{nM}$ (Visser et al., 1979)], and either NADPH or GSH (various final concentrations) in PB-EDTA or buffer, in a final volume of $300 \mu \mathrm{l}$. In controls without microsomes or without cytosol, buffer was used instead to determine non-specifically released free ${ }^{125} I$, which was subtracted from observed counts (usually less than $2 \%$ of total c.p.m.).

When assays were performed with cytosolic fractions $A$ and $B$, they were modified as follows: in reconstitution experiments with fraction A, fraction B and NADPH, the reaction mixtures consisted of various combinations of microsomes $(22 \mu \mathrm{g}$ of protein), fraction A $(142 \mu \mathrm{g}$ of protein), fraction B ( $23 \mu \mathrm{g}$ of protein), NADPH (final concn. $1 \mathrm{mM}$ ), $\left[{ }^{125} \mathrm{I}\right] \mathrm{rT}_{3}$ in PB-EDTA ( $10^{5}$ c.p.m.; final $\mathrm{rT}_{3}$ substrate concn. 0.21 nM) and PB-EDTA in a final volume of $300 \mu \mathrm{l}$. After incubation for $15 \mathrm{~min}$ at $30^{\circ} \mathrm{C}$, $500 \mu \mathrm{l}$ of human serum and $500 \mu \mathrm{l}$ of $10 \%(\mathrm{w} / \mathrm{v})$ trichloroacetic acid were added and the mixture centrifuged; counts in $500 \mu 1$ of supernatant (S), as well as the remainder in the tube (P), were then determined.

Relative 5'-deiodination rates were expressed as follows: 


$$
{ }^{125} \mathrm{I}^{-} \text {released }(\%)=\frac{\text { c.p.m. in } S}{\text { c.p.m. in } S+\text { c.p.m. in } \mathrm{P}} \times 100
$$

Correction was made for radioactivity counts of control tubes containing buffer and $\left[{ }^{125} I\right] \mathrm{rT}_{3}$ only.

The percentage of ${ }^{125} \mathrm{I}^{-}$released with respect to incubation time was linear up to $30 \mathrm{~min}$ under the conditions used. The free ${ }^{125} \mathrm{I}^{-}$content in the reaction mixtures was 2.4 times higher than that in the $500 \mu \mathrm{l}$ of supernatant, on the basis of a comparison with paper chromatography. Therefore $1 \%$ of ${ }^{125} \mathrm{I}^{-}$released is $2.4 \%$ of the ${ }^{125} \mathrm{I}^{-}$produced/tube. Since the $3^{\prime}$ or $5^{\prime}$ position is randomly labelled, $1 \%{ }^{125} \mathrm{I}^{-}$released is equivalent to 4.8 $(2.0 \times 2.4 \times 1) \%$ deiodination or $3.0 \mathrm{fmol}$ of rT3 deiodinated.

Control tubes containing microsomes and/or cytosol denatured by heat at $90^{\circ} \mathrm{C}$ for 5 min or containing buffer instead of denatured microsomes and/or cytosol were incubated under the same conditions as the samples. The free ${ }^{125} \mathrm{I}^{-}$content in the supernatant in the presence of denatured microsomes and/or cytosol was the same as that in the buffer. The effects of NADPH and GSH in the presence of buffer alone at the same time were also studied, but no influence of these materials on the free ${ }^{125} \mathrm{I}^{-}$content of the trichloroacetic acid supernatant was observed. Therefore tubes containing buffer instead of microsomes, cytosol, fraction A or fraction B were used as controls. The free ${ }^{125} \mathrm{I}^{-}$content in the presence of buffer alone did not increase between 0 and $15 \mathrm{~min}$.

\section{Determination of endogenous glutathione (GSH + GSSG)}

GSH + GSSG was determined by using the enzymic assay described previously (Tietze, 1969).

\section{Determination of protein concentrations}

Protein concentrations were determined by the method of Lowry et al. (1951), with bovine serum albumin as a standard.

\section{Statistics}

Statistical analyses of the data were performed by a non-paired Student's $t$ test to obtain two-tailed $P$ values, with $P<0.05$ considered to be significant.

\section{RESULTS}

\section{Effects of NADPH and GSH on microsomal 5'-DI activity}

By using washed microsomes and cytosol, the effects of various concentrations of NADPH and GSH on $5^{\prime}$-DI activity were studied. As Table 1 shows, cytosol had no stimulatory effect on 5 -DI activity of washed microsomes in the absence of NADPH or GSH, whereas $62 \mu \mathrm{M}$ NADPH was sufficient to attain almost maximal $5^{\prime}$-DI activity in the presence of cytosol. On the other hand, GSH had a stimulatory effect on the 5'-DI activity of washed microsomes in the absence of cytosol, whereas NADPH had none. Although both NADPH and GSH each had a stimulatory effect on washed microsomes in the presence of cytosol, the $5^{\prime}$-DI activity with cytosol and $62 \mu \mathrm{M}-\mathrm{NADPH}$ was consistently higher than that with cytosol and $250 \mu \mathrm{M}-\mathrm{GSH}$.

Effects of dialysis of cytosol on microsomal 5'-DI activity

More than $90 \%$ of endogenous GSH + GSSG was removed by dialysis. When microsomes were mixed with dialysed cytosol in the absence of NADPH, the deiodinase activity was very low. However, as Table 2 shows, the activity was increased nearly 8-fold if NADPH was also added $(P<0.001)$.

\section{5 -DI activity in reconstitution mixtures using fractions from Sephadex G-50 column chromatography}

Since reconstitution experiments using microsomes and NADPH indicated that cytosol was required for stimulation of $5^{\prime}$-deiodination, cytosol was fractionated; microsomes and NADPH were mixed with each fraction obtained by column chromatography on Sephadex G-50 to identify fractions containing activator activity. A slight

Table 1. Effects of NADPH and GSH on microsomal 5'-deiodination

5'-DI activities of washed microsomes $(22 \mu \mathrm{g})$ and cytosol $(2000 \mu \mathrm{g})$, cytosol alone and washed microsomes were determined in the presence of various concentrations of NADPH $(a)$ or GSH $(b)$. Values are means \pm S.D. for six determinations.

$(a)$

Addition

Microsomes and cytosol

Cytosol

Microsomes

(b)

Addition

Microsomes and cytosol

Cytosol

Microsomes

$5^{\prime}$-DI activity $\left(\%\right.$ of ${ }^{125} \mathrm{I}^{-}$released $\left./ 15 \mathrm{~min}\right)$

\begin{tabular}{cccc}
\hline 0 & 62 & 250 & 1000 \\
\hline $2.4 \pm 0.15$ & $7.5 \pm 0.23^{*}$ & $8.1 \pm 0.26^{*}$ & $8.6 \pm 0.23$ \\
$2.2 \pm 0.14$ & $4.7 \pm 0.11$ & $4.9 \pm 0.19$ & $5.4 \pm 0.17$ \\
$0.6 \pm 0.11$ & $0.3 \pm 0.15$ & $0.3 \pm 0.11$ & $0.2 \pm 0.09$
\end{tabular}

$5^{\prime}$-DI activity $\left(\%\right.$ of ${ }^{125} \mathrm{I}^{-}$released $\left./ 15 \mathrm{~min}\right)$

* $P<0.001$ for $5^{\prime}$-DI activity with NADPH versus that with GSH.

Vol. 234 
Table 2. Effect of dialysed cytosol on 5'-DI activity

The reaction was started by adding $\left[{ }^{125} \mathrm{I}\right] \mathrm{rT}_{3}$ to the reaction mixtures. Note that the effect of NADPH is pronounced only when dialysed cytosol was present. Values are means \pm S.D. for six determinations. $P<0.001$ for a versus $\mathrm{b}$ and $\mathrm{f} ; P<0.001$ for $\mathrm{c}$ versus $\mathrm{f}$.

\begin{tabular}{ccccc}
\hline Code & $\begin{array}{c}\text { Dialysed } \\
\text { cytosol } \\
(1 \mathrm{mM})\end{array}$ & $\begin{array}{c}\text { Microsomes } \\
\text { of protein })\end{array}$ & $\begin{array}{c}5^{\prime} \text {-DI activity } \\
(22 \mu \mathrm{g} \text { of } \\
\text { protein })\end{array}$ & $\begin{array}{c}{ }^{125} \mathrm{I}^{-} \text {released/ } \\
15 \mathrm{~min})\end{array}$ \\
\hline $\mathrm{a}$ & + & + & + & $8.22 \pm 0.37$ \\
$\mathrm{~b}$ & - & + & + & $1.05 \pm 0.23$ \\
$\mathrm{c}$ & - & - & + & $1.05 \pm 0.09$ \\
$\mathrm{~d}$ & - & + & - & $0.45 \pm 0.05$ \\
$\mathrm{e}$ & + & + & - & $2.63 \pm 0.16$ \\
$\mathrm{f}$ & + & - & + & $0.48 \pm 0.13$ \\
\hline
\end{tabular}

increase of $5^{\prime}$-DI activity was observed among the fractions at the void volume (results not shown). Fractions at the void volume (fractions no. 19-23 in Fig. 1) were then collected (designated 'fraction $A$ ') and reconstituted with each fraction from the column in the presence of microsomes and $1 \mathrm{~mm}-\mathrm{NADPH}$. As Fig. 1 shows, three peaks of $5^{\prime}$-DI-stimulating activity were thus obtained, with the highest $5^{\prime}$-DI activity in fraction no. 36. The elution position of the second peak (designated 'fraction B') was almost the same as that of ribonuclease A (chromatographed separately on the same column), thereby indicating its $M_{\mathrm{r}}$ to be approx. 13000. Similarly, the third peak (designated 'fraction C') was found to be of low $M_{\mathrm{r}}$, similar to that of GSH (300), since it coincided with the distribution of endogenous GSH $\left(M_{\mathrm{r}} 300\right)+$ GSSG among the fractions. Fractions 34-39 (Fig. 1) were pooled and used as fraction $B$. When similar reconstitution experiments using fraction $B$ (instead of fraction $A$ ), NADPH and microsomes were performed, activity of 5'-DI corresponding to peak A in Fig. 1 was found, but none corresponding to peak $\mathrm{B}$ or $\mathrm{C}$ (results not shown).

Dialysed cytosol was also fractionated by Sephadex G-50 as described above for undialysed cytosol and the 5 -DI-stimulating activity of each fraction was determined with fraction $\mathrm{A}$ and NADPH. Although no peak $\mathrm{C}$ corresponding to that in Fig. 1 was found, peaks $A$ and $B$ were observed among the fractions (results not shown), confirming that the active cytosol components in $\mathrm{A}$ and $B$ are non-dialysable.

\section{Effects of NADPH on the activity of $5^{\prime}$-DI}

The effects of various concentrations of NADPH on $5^{\prime}$-DI activity were studied by using constant concentrations of fraction A, fraction B and microsomes. As Fig. 2 shows, the activity of 5'-DI was greatly increased by the addition of $62 \mu \mathrm{M}-\mathrm{NADPH}(P<0.001)$. However, at concentrations greater than $125 \mu \mathrm{M}, \mathrm{NADPH}$-induced activity began to decrease, reaching approx. $67 \%$ of maximal activity at $1 \mathrm{~mm}$.

\section{Effect of various concentrations of microsomes, fraction B} and fraction $A$ on $5^{\prime}$-DI activity

As Fig. 3(a) shows, 5'-DI activity was linear up to $22 \mu \mathrm{g}$ of microsomal protein $/ 300 \mu$ l of reaction mixture in the

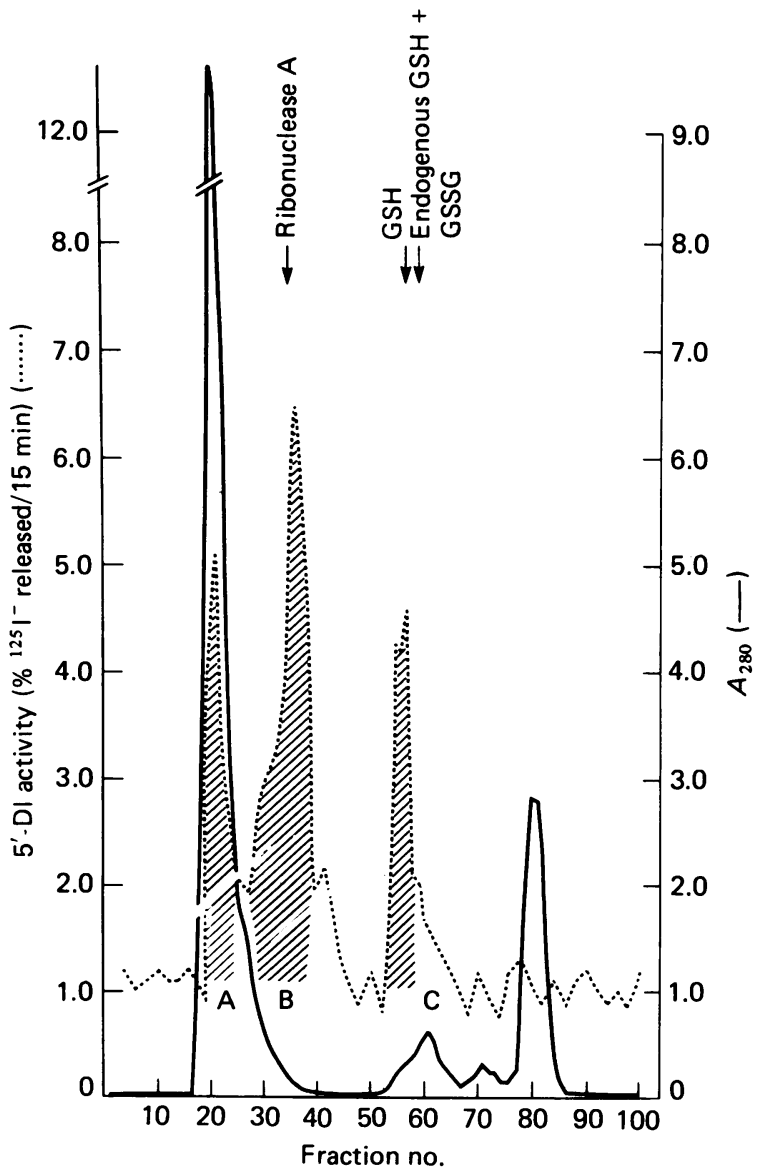

Fig. 1. Sephadex G-50 column chromatography of cytosol and 5 '-DI activity in the reconstitution experiments using each fraction from the column

Fractions $(2 \mathrm{ml})$ were collected during elution of the Sephadex G-50 column $(1.5 \mathrm{~cm} \times 60 \mathrm{~cm})$ with PB-EDTA. Column effluent was monitored for absorbance at $280 \mathrm{~nm}$. $5^{\prime}$-DI activity was assayed, each fraction $(100 \mu \mathrm{l})$ being mixed with fraction A $(142 \mu \mathrm{g}$ of protein $/ 50 \mu \mathrm{l})$ in the presence of $1 \mathrm{mM}-\mathrm{NADPH}$ and microsomes $(22 \mu \mathrm{g}$ of protein $/ 50 \mu \mathrm{l})$. The reaction was started by adding $\left[{ }^{125} \mathrm{I}\right] \mathrm{rT}_{3}(100000$ c.p.m.) in a final volume of $300 \mu \mathrm{l}$. Three major peaks of 5 -DI-stimulating activity (see hatched areas) were noted (A, B and $\mathrm{C}$ ). The elution positions of ribonuclease A $\left(M_{\mathrm{r}}\right.$ 13700) and GSH $\left(M_{\mathrm{r}} 307\right)$ are shown at the top. Endogenous GSH + GSSG is shown by arrows at the top.

presence of fixed concentrations of A, B and NADPH, and was significantly higher than the activity without NADPH $[P<0.001$ at each concentration $(7-42 \mu \mathrm{g}$ of protein) of microsomes].

As Fig. 3(b) shows, 5'-DI activity was proportional to the concentrations of fraction $B$ added in the presence of fixed concentrations of $\mathrm{A}$, microsomes and NADPH ( $1 \mathrm{mM}$ ), but $5^{\prime}$-DI activity was not increased by $B$ if NADPH was omitted.

As shown in Fig. 3(c), 5'-DI activity was also increased when the concentration of fraction $A$ was increased in the presence of fixed concentrations of $\mathbf{B}$, microsomes and NADPH. A slight increase of 5'-DI activity with increasing concentrations of $A$ was noted when NADPH was omitted. 


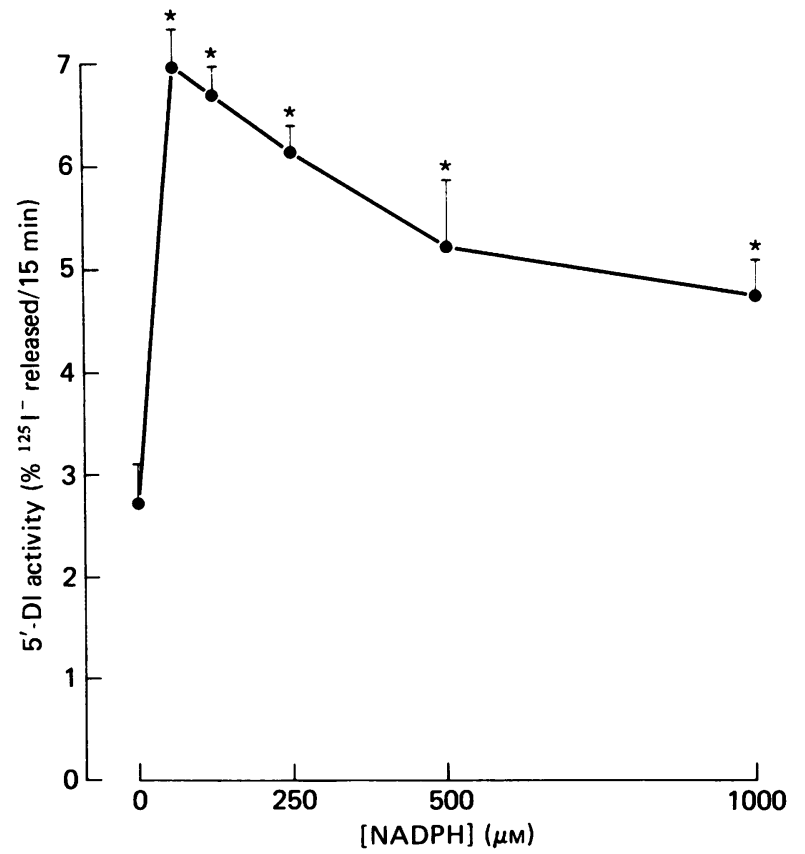

Fig. 2. Effect of NADPH on $5^{\prime}$-deiodinase activity in the reconstitution experiments

The reaction mixtures contained various concentrations of NADPH, fraction A (142 $\mu \mathrm{g})$, fraction B $(23 \mu \mathrm{g})$, and microsomes $(22 \mu \mathrm{g})$ in a final volume of $300 \mu \mathrm{l}$. The
Effects of heating of fraction $A$ and fraction $B$ on the 5'-DI activity

Fraction $\mathrm{A}$ and fraction $\mathrm{B}$ were heated at $56^{\circ} \mathrm{C}$ for $10 \mathrm{~min}$ before reconstitution experiments were performed. As shown in Table 3, $5^{\prime}$-DI activity was decreased by $50 \%$ if heated fraction $A$ was used in the presence of unheated fraction $\mathrm{B}$, microsomes and $1 \mathrm{mM}-\mathrm{NADPH}(P<0.001)$. However, fraction B was heat-stable.

\section{Effect on 5'-DI activity of replacing fraction A with yeast glutathione reductase}

Since rat liver is reported to contain endogenous glutathione reductase (Mize \& Langdon, 1962), which would be a constituent of fraction $A$, the effects of exogenous yeast glutathione reductase (instead of fraction A) on 5'-DI activity were studied with fraction $\mathrm{B}$, microsomes and NADPH $(1 \mathrm{mM})$. The $5^{\prime}$-DI activity did not increase with increasing concentrations of added reductase up to 4 units/tube (results not shown).

reaction was started by adding $\left[{ }^{125} \mathrm{I}\right] \mathrm{rT}{ }_{3}(100000$ c.p.m. $)$ to the reaction mixtures. Results are presented as means \pm S.D. from six determinations. ${ }^{*} P<0.001$ for the activity at $0 \mu \mathrm{M}-\mathrm{NADPH}$ versus that at $62,250,500$ and $1000 \mu \mathrm{M}-$ NADPH (final concns.).
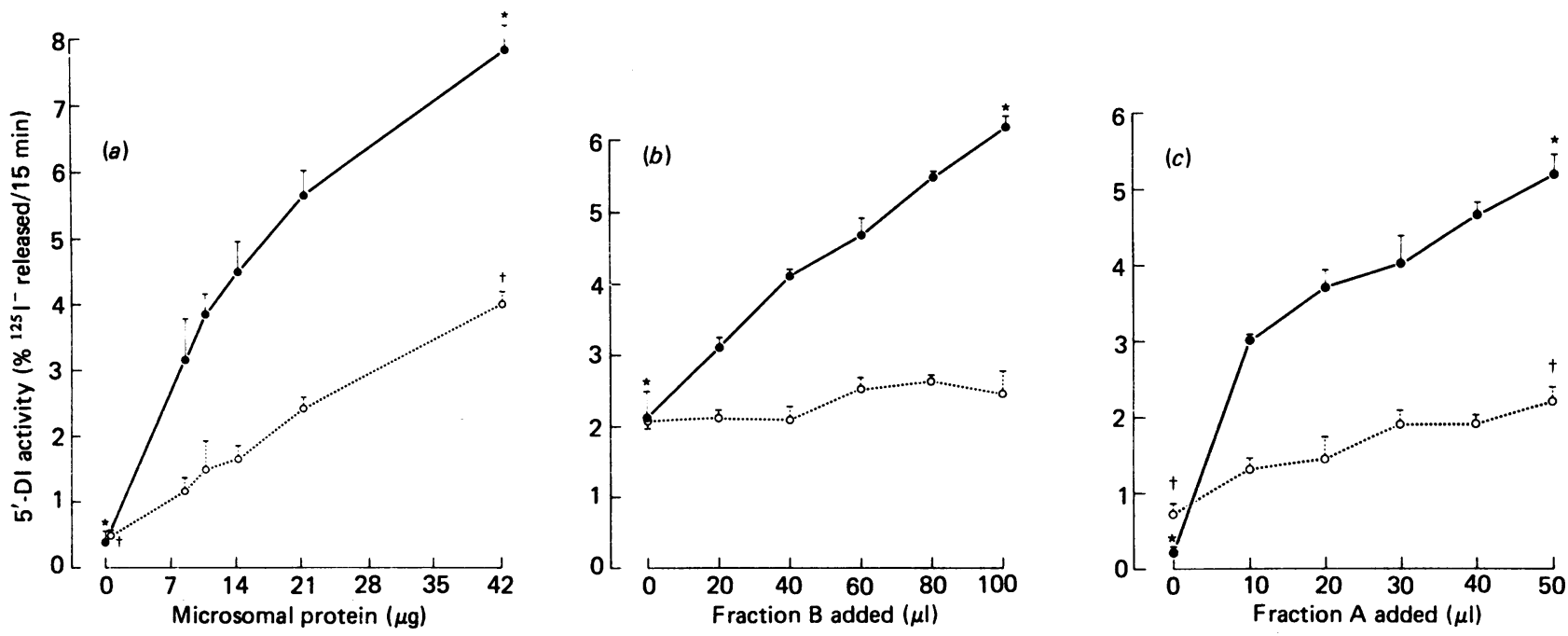

Fig. 3. Effect of various concentrations of microsomal protein (a), fraction B (b) and fraction $A$ (c)

(a) Fraction A (142 $\mu \mathrm{g})$, fraction B (23 $\mu \mathrm{g})$, and various concentrations of microsomal proteins were mixed with $1 \mathrm{mm-NADPH}$ $(-)$ or with buffer instead of NADPH $(\cdots)$ ). The reaction was started by adding ${ }^{125} I^{-}$rT ${ }_{3}(100000$ c.p.m.) to each tube. Results are presented as means \pm S.D. from six determinations. ${ }^{*}, \dagger P<0.001$ for the $5^{\prime}$-DI activities in the presence of microsomes (at $42 \mu \mathrm{g}$ of protein) versus those in the absence of microsomes. (b) Fraction A (142 $\mu \mathrm{g})$, microsomes (22 $\mu \mathrm{g})$, and various concentrations of fraction B were mixed with $1 \mathrm{mM-NADPH}(-)$ or with buffer instead of NADPH $(\cdots \cdots)$. A $100 \mu$ l portion of fraction B contained $23 \mu \mathrm{g}$ of protein. Results are presented as means \pm S.D. from six determinations. ${ }^{*} P<0.001$ for the activity with $0 \mu \mathrm{l}$ of fraction B versus that with $100 \mu \mathrm{l}$ of fraction B. (c) Fraction B (23 $\mu \mathrm{g})$, microsomes $(22 \mu \mathrm{g})$, and various concentrations of fraction A were mixed with 1 mM-NADPH $(-)$ or with buffer instead of NADPH ( $\cdots \cdots)$. Fraction A contained $142 \mu \mathrm{g}$ of protein $/ 50 \mu \mathrm{l}$. The reaction was started by adding [ $\left.{ }^{125} \mathrm{I}\right] \mathrm{rT} \mathrm{T}_{3}(100000 \mathrm{c.p} . \mathrm{m}$.) to the tubes. Results are presented as means \pm S.D. from six determinations. ${ }^{*} P<0.001$ for the activity with $0 \mu \mathrm{l}$ of fraction $\mathrm{A}$ versus with $50 \mu \mathrm{l}$ of fraction $\mathrm{A}$ in the presence of NADPH. $\dagger P<0.01$ for the activity with $0 \mu \mathrm{l}$ of fraction A versus with $50 \mu l$ of fraction $A$ in the absence of NADPH. ${ }^{*}+P<0.001$ for the activity with NADPH versus without NADPH, both without fraction $A$ added. 
Table 3. Effects of heated fractions $A$ and $B$ on the 5'-DI activity

When heated fractions were used they had been heated at $56^{\circ} \mathrm{C}$ for $10 \mathrm{~min}$. Values are means \pm S.D. from four determinations. $P<0.001$ for a versus $\mathrm{b}$ and $\mathrm{d} ; P<0.001$ for $\mathrm{c}$ versus $\mathrm{b}$ and $\mathrm{d} ; \boldsymbol{P}<0.001$ for $\mathrm{e}$ versus $\mathrm{f}$.

\begin{tabular}{|c|c|c|c|c|c|c|c|}
\hline Code & $\begin{array}{l}\text { NADPH } \\
(1 \mathrm{mM})\end{array}$ & $\begin{array}{c}\text { Heated } \\
\text { fraction } \\
\text { B }(23 \mu \mathrm{g})\end{array}$ & $\begin{array}{c}\text { Heated } \\
\text { fraction } \\
\text { A }(142 \mu \mathrm{g})\end{array}$ & $\begin{array}{l}\text { Fraction } \\
\text { B }(23 \mu \mathrm{g})\end{array}$ & $\begin{array}{c}\text { Fraction } \\
\text { A }(142 \mu \mathrm{g})\end{array}$ & $\begin{array}{l}\text { Microsomes } \\
\quad(22 \mu \mathrm{g})\end{array}$ & $\begin{array}{c}5^{\prime} \text {-DI activity } \\
\left(\%{ }^{125} I^{-} \text {released } /\right. \\
15 \text { min })\end{array}$ \\
\hline a & + & - & - & + & + & + & $4.18 \pm 0.37$ \\
\hline b & + & - & + & + & - & + & $2.18 \pm 0.04$ \\
\hline c & + & + & - & - & + & + & $4.33 \pm 0.44$ \\
\hline $\mathrm{d}$ & + & + & + & - & - & + & $2.20 \pm 0.27$ \\
\hline $\mathrm{e}$ & - & - & - & - & - & + & $1.05 \pm 0.09$ \\
\hline f & + & - & - & - & - & + & $0.48 \pm 0.13$ \\
\hline
\end{tabular}

\section{DISCUSSION}

Our studies with washed microsomes have demonstrated a marked stimulation of 5'-deiodination of [125I]rT $\mathrm{T}_{3}$ by NADPH in the presence of cytosol. [ $\left.{ }^{125} \mathrm{I}\right] \mathrm{rT}_{3}$ was employed as substrate, since in liver it is rapidly deiodinated (Eisenstein et al., 1980) to $3,3^{\prime}-\mathrm{T}_{2}$ and $\mathrm{I}^{-}$in equivalent proportions during the early stage (Hufner \& Grussendorf, 1978; Leonard \& Rosenberg, 1980b), whereas deiodination of [ $\left.{ }^{125} \mathrm{I}\right] \mathrm{T}_{4}$ is more complex (Balsam \& Ingbar, 1979; Balsam et al., 1979). In other experiments (results not shown) we have also found a similar stimulatory effect on the conversion in vitro of non-radioactive $\mathrm{T}_{4}$ (at $6.4 \mu \mathrm{M}$ ) into $\mathrm{T}_{3}$. Some workers demonstrated a stimulatory effect of NADPH on the activity of hepatic 5'-deiodination of $\mathrm{T}_{4}$ in fed or fasted rats, whereas others could not (Visser et al., 1975; Chiraseveenuprapund et al., 1978; Balsam \& Ingbar, 1979; Balsam et al., 1979; Sato et al., 1981). These discrepancies may be explained by the differences in the level of endogenous NADPH within the tissues used. Alterations in hepatic NADPH concentrations can be mediated by changes in nutritional status of the animals (Anderson \& Hollifield, 1966; Rudack et al., 1971; Szepesi et al., 1971), as well as by the uncontrolled metabolic breakdown or oxidation of NADPH during tissue processing and storage (Bücher, 1970; Sato et al., 1981). Hence, our procedures, which routinely used processed and stored tissue fractions, may have depleted NADPH content and thus augmented dependence of our assay system on NADPH to an extent that would not have been as apparent with freshly prepared material.

Interpretation of the effect of NADPH on the 5 -deiodination of $T_{4}$ to $T_{3}$ in this tissue is further complicated by the possible inhibition of $5^{\prime}$-deiodination of $\mathrm{T}_{4}$ by an NADPH-generating system (Balsam \& Ingbar, 1979). Our data indicate that the 5'-DI of rat liver microsomes can also be inhibited when excessive (i.e. $1 \mathrm{~mm}$ ) NADPH is added (Table 2, c versus f; Table 3, e versus f; Fig. 2), a finding which appears to be consistent with that of others (Balsam et al., 1979), but which requires further investigation.

The apparent stimulatory effect on $5^{\prime}$-DI activity in the presence of cytosol, but in the absence of microsomes (see Table 1) may be explained by the presence of non-sedimenting (soluble) deiodinase present in the cytosol, even after repeated ultracentrifugation. If the considerably larger amount of cytosolic protein $(2000 \mu \mathrm{g}$ per tube) present during incubation compared with that of microsomal protein ( $22 \mu \mathrm{g}$ per tube) is taken into account, the reason for the apparently high $5^{\prime}$-DI activity observed in cytosol alone, which at times exceeds that obtained by microsomes alone (see Table 1), can be explained. Nevertheless, the combination of both microsomes and cytosol produces an effect of NADPH that is clearly not simply additive but rather synergistic, thereby demonstrating an interaction between a cytosolic cofactor and microsomal deiodinase in the presence of NADPH which may play a crucial role in the regulation of hepatic deiodination of iodothyronines.

From the results of preliminary experiments with whole cytosol, it was apparent that the stimulatory effect of NADPH is not mediated by glutathione reductase alone, since $62 \mu \mathrm{M}-\mathrm{NADPH}$ (equivalent to $124 \mu \mathrm{M}$-GSH) produced a greater effect than $250 \mu \mathrm{M}-\mathrm{GSH}$. To discover, therefore, what factors are involved in the microsomal 5'-deiodination, Sephadex G-50 chromatography was employed to fractionate cytosol. Our findings on the stimulatory effect of a low- $M_{\mathrm{r}}$ cytosolic component (fraction C in Fig. 1) are in agreement with the previous report by Imai et al. (1980), who identified an activator of microsomal deiodinase as GSH. We confirm that the constituents responsible for this effect are GSH + GSSG, on the basis of their direct measurement and the elution pattern of an exogenous standard. Such observations are consistent with the established role of thiol in mediating hepatic deiodinase (Visser et al., 1976) and the previously recognized direct stimulatory effect of GSH (Chopra, 1978; Imai et al., 1980).

However, in the present study we have demonstrated that the cytosolic factors involved in the NADPHdependent reductase system which stimulates $5^{\prime}$-DI deiodination as recently reported (Sawada et al., 1985a), do not involve glutathione, since enhanced deiodination can be produced in the absence of the lower- $M_{\mathrm{r}}$ fraction C. Although chromatographic fractions $A$ and $B$ are heterogeneous, it appeared that NADPH-dependent reductase in fraction $A$ and a hydrogen acceptor in fraction $B$ were involved in the activation of 5'deiodination. A possible deiodination reaction sequence consistent with our data is shown in Scheme 1. A component of fraction B (a hydrogen carrier) undergoes reduction by NADPH, mediated by reductase present in fraction A. Subsequently, 5'-DI, oxidized during deiodination of $\mathrm{rT}_{3}$, is reduced by component $\mathrm{B}$ (the hydrogen carrier) in fraction B. Such a reductase system represents a further extension of the possible mechanism proposed 


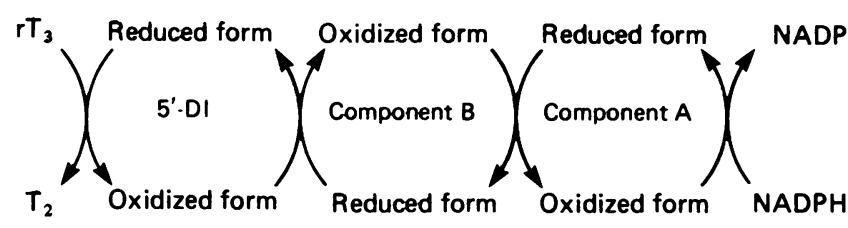

Scheme 1. Hypothetical model for reaction sequences involved in $5^{\prime}$-deiodination of $\left[^{125}{ }^{1} \mathrm{rT}_{3}\right.$ involving hydrogen transfer

5'-DI undergoes cyclic oxidation-reduction reaction with reactive thiol groups of the enzyme in the presence of fraction A, fraction B and NADPH during 5 '-deiodination. See the text for a detailed explanation.

by others (Leonard \& Rosenberg, 1978; Visser, 1979) by our finding that endogenous reduced hepatic cytosolic component B can substitute for another thiol such as GSH, DTT or, as recently reported by our laboratory, dihydrolipoamide or its generating system (Sawada et al., $1985 c$ ). The findings presented here represent the first demonstration of $5^{\prime}$-DI activation in a system which contained neither GSH nor added exogenous thiol and indicate the existence of a heretofore unrecognized endogenous activating system of high efficiency, which is quite distinct from other activating systems involving glutathione-glutathione reductase or NADPH alone (Balsam \& Ingbar, 1979; Balsam et al., 1979; Harris et al., 1979).

The existence in vivo of two such parallel deiodinase activation sequences (involving reductases specific for GSSG and component B) may explain some of the apparent discrepancies between previous reports on characteristics of the cytosolic cofactor and its role in regulating the peripheral metabolism of iodothyronine (Sato \& Robbins, 1984). Thus oxidation or depletion of component B, NADPH or GSH, increase in levels of GSSG, and inactivation or depletion of component B reductase or GSH reductase (both present in component A) are all factors which must be taken into account in explaining changes in deiodinase activity.

Although the physical and enzymic characteristics of the constituents of fractions A and B which may be involved in the reactions shown in Scheme 1 require further characterization, the system described herein appears similar to the thioredoxin-thioredoxin reductase system that plays a role in ribonucleotide reduction and possibly other biological reductions (Larsson, 1973; Holmgren, 1980; Luthman \& Holmgren, 1982) for the following reasons: $(a)$ the $M_{\mathrm{r}}$ of component B (approx. 13000 ) is similar to that of thioredoxin from rat liver (12000); (b) component B, like thioredoxin, is heat-stable; and $(c)$ both systems are NADPH-dependent. Furthermore, stimulation of 5'-DI was achieved in the presence of fraction A, fraction B and NADPH in the presence of microsomes, suggesting that the thiol group known to be required for iodothyronine deiodination (Visser et al., 1976; Chopra, 1978; Leonard \& Rosenberg, 1978) could have been generated by reduction of component $B$ by NADPH in a manner similar to the reduction of thioredoxin. Hence, the cytosolic cofactors mediating 5 -deiodination may not only provide an endogenous thiol, but may also increase the efficiency of deiodination through allosteric alteration of the enzyme by binding of the cofactor. However, further studies will be required to elucidate more precisely the structure of the cofactor and the mechanism of its action.

Since this paper was originally submitted, Goswami \& Rosenberg (1985) have reported the isolation of a hepatic cytosolic protein factor ('SPF') with an $M_{\mathrm{r}}$ of 11000 which enhanced 5'-DI activity in the presence of GSH by a glutaredoxin-like activity. However, the Factor B described in the present paper appears to be different, since it has an absolute requirement for NADPH and is clearly active in the absence of GSH.

\section{Note added in proof}

(Received 19 December 1985)

Furthermore, when fractions A and B were assayed by using $\mathrm{Nbs}_{2}$ (Tietze, 1969), either before or after reduction with $\mathrm{NaBH}_{4}$, the GSH concentration was found to be negligible $(<10 \mu \mathrm{M})$, thus confirming that the $5^{\prime}$-DI activation system described above functions without GSH in either a free or a mixed disulphide form.

This investigation was supported by grant no. MA-8092 from the Medical Research Council of Canada. K.S. was the recipient of a Research Fellowship from the Mount Sinai Hospital Department of Medicine Research Fund. The excellent technical assistance of Mrs. E. Gera and Mr. P. Fung in the performance of these studies, and the secretarial help of Ms. D. Cartwright in the preparation of the manuscript, are greatly appreciated.

\section{REFERENCES}

Anderson, H. \& Hollifield, G. (1966) Metab. Clin. Exp. 15, 1098-1103

Balsam, A. \& Ingbar, S. H. (1979) J. Clin. Invest. 63, 1145-1156

Balsam, A., Sexton, H. \& Ingbar, S. H. (1979) Endocrinology (Baltimore) 105,1115-1121

Bücher, T. (1970) in Pyridine Nucleotide-Dependent Dehydrogenases (Sund, H., ed.), pp. 339-461, Springer-Verlag, Berlin, Heidelberg and New York

Chiraseveenuprapund, P., Buergi, U., Goswami, A. \& Rosenberg, I. M. (1978) Endocrinology (Baltimore) 102, 612-622

Chopra, I. J. (1978) Science 199, 904-906

Eisenstein, Z., Balsam, A., Garber, J. \& Ingbar, S. H. (1980) Endocrinology (Baltimore) 107, 530-537

Fekkes, D., Hennemann, G. \& Visser, T. J. (1983) Biochim. Biophys. Acta 742, 324-333

Gavin, L. A., McMahon, J. A. \& Moeller, M. (1980) J. Clin. Invest. 65, 943-946

Goswami, A. \& Rosenberg, I. N. (1985) J. Biol. Chem. 260, 6012-6019

Harris, A. R. C., Fang, S.-L., Hinerfeld, L., Braverman, L. E. \& Vagenakis, A. G. (1979) J. Clin. Invest. 63, 516-524

Holmgren, A. (1980) Experientia Suppl. 36, 149-180

Hufner, M. \& Grussendorf, M. (1978) Clin. Chim. Acta 85, 243-251

Imai, Y., Kataoka, K., \& Nishikimi, M. (1980) Endocrinol. Jpn. 27, 201-207

Larsson, A. (1973) Eur. J. Biochem. 35, 346-349

Leonard, J. K. \& Rosenberg, I. N. (1978) Endocrinology (Baltimore) 103, 2137-2144

Leonard, J. K. \& Rosenberg, I. N. (1980a) Endocrinology (Baltimore) 106, 444-451

Leonard, J. K. \& Rosenberg, I. N. (1980b) Endocrinology (Baltimore) 107, 1376-1383

Lowry, O. H., Rosebrough, N. J., Farr, A. L. \& Randall, R. J. (1951) J. Biol. Chem. 193, 265-275

Luthman, M. \& Holmgren. A. (1982) Biochemistry 21, 6628-6633

Mize, C. \& Langdon, R. G. (1962) J. Biol. Chem. 237, 1589-1595 
Riddles, P. W., Blakeley, R. L. \& Zerner, B. (1983) Methods Enzymol. 91, 49-60

Rudack, D., Chisholm, E. M. \& Holton, D. (1971) J. Biol. Chem. 246, 1249-1254

Sato, K. \& Robbins, J. (1981) Endocrinology (Baltimore) 109, 844-852

Sato, K. \& Robbins, J. (1984) in Peripheral Metabolism of Thyroxine (Loos, V. \& Wartofsky, L., eds.), pp. 30-35, Thieme-Stratton, New York

Sato, T., Maruyamas, S. \& Namura, K. (1981) Endocrinol. Jn. 28, 457-459

Sawada, K., Hummel, B. C. W. \& Walfish, P. G. (1985a) Program Abstr. Ann. Meet. Endocrine Soc. 67th, Baltimore, abstr. 1110

Sawada, K., Hummel, B. C. W. \& Walfish, P. G. (1985b) Int. Thyroid Congress 9th, Sao Paulo, Brazil, p. 149 (abstr. 217)

Received 10 May 1985/27 September 1985; accepted 4 November 1985
Sawada, K., Hummel, B. C. W. \& Walfish, P. G. (1985c) Endocrinology (Baltimore) 117, 1259-1263

Szepesi, B., Berdanier, C. D., Diachenko, S. K. \& Moser, P. B. (1971) J. Nutr. 101, 1147-1152

Tietze, F. (1969) Anal. Biochem. 27, 502-522

Visser, T. J. (1978) Mol. Cell. Endocrinol. 10, 241-247

Visser, T. J. (1979) Biochim. Biophys. Acta 569, 302-308

Visser, T. J., van der Does-Tobe, I., Docter, R. \& Hennemann, G. (1975) Biochem. J. 150, 489-493

Visser, T. J., van der Does-Tobe, I., Docter, R. \& Hennemann, G. (1976) Biochem. J. 157, 479-482

Visser, T. J., Fekkes, D., Docter, R. \& Hennemann, G. (1978) Biochem. J. 174, 221-229

Visser, T. J., Fekkes, D., Docter, R. \& Hennemann, G. (1979) Biochem. J. 179, 489-495

Visser, T. J., Leonard, J. L., Kaplan, M. M. \& Larsen, P. R. (1982) Proc. Natl. Acad. Sci. U.S.A. 79, 5080-5084 